\title{
Location of submacular hemorrhage as a predictor of visual outcome after intravitreal ranibizumab for age-related macular degeneration
}

This article was published in the following Dove Press journal:

Clinical Interventions in Aging

3 November 2017

Number of times this article has been viewed

\author{
Dimitrios Karagiannis' \\ Irini Chatziralli' \\ Konstantinos Kaprinis' \\ Ilias Georgalas ${ }^{2}$ \\ Efstratios Parikakis' \\ Panagiotis Mitropoulos' \\ 'Second Department of \\ Ophthalmology, Ophthalmiatrion \\ Athinon, Athens, Greece; ${ }^{2}$ First \\ Department of Ophthalmology, \\ University of Athens, Athens, Greece
}

Purpose: To evaluate the anatomical and functional outcomes in patients with submacular hemorrhage (SMH) due to age-related macular degeneration (AMD) treated with ranibizumab, and to evaluate the potential role of the SMH location in the final outcome after treatment.

Methods: Participants in this study were 12 treatment-naïve patients with SMH due to neovascular AMD who were treated with intravitreal ranibizumab and had at least 12 months' follow-up. All patients underwent best-corrected visual acuity measurement and optical coherence tomography at baseline and at every visit posttreatment, while fluorescein angiography was done at baseline and at the discretion of the physician thereafter.

Results: Of the patients, $83.4 \%$ showed improvement or stabilization in best-corrected visual acuity after treatment at the 12-month follow-up, with a mean number of $7.3 \pm 2.9$ injections. Patients with SMH surrounding the foveal area in $360^{\circ}$ presented worse anatomical and functional outcomes compared to those with SMH adjacent to the fovea.

Conclusion: Intravitreal ranibizumab seems to be safe and effective, either improving or stabilizing visual acuity, in patients with SMH due to wet AMD. The location of the SMH may predict the final outcome after treatment.

Keywords: age-related macular degeneration, ranibizumab, submacular hemorrhage, treatment

\section{Introduction}

Age-related macular degeneration (AMD) is the leading cause of visual loss in patients $>55$ years old. ${ }^{1}$ Submacular hemorrhage $(\mathrm{SMH})$ is an accumulation of blood between the neurosensory retina and the retinal pigment epithelium (RPE), arising from the choroidal or retinal circulation within the macular region, and is considered to occur usually in the context of neovascular AMD. ${ }^{2}$ SMH due to AMD can cause progressive or sudden visual loss, dependent on the extent and thickness of the hemorrhage, while the natural history of $\mathrm{SMH}$ has poor prognosis, resulting in final visual acuity (VA) of $<20 / 200$ in about half of cases. ${ }^{2,3}$ In fact, subretinal blood seems to be toxic to the retina, causing irreversible retinal damage. A potential mechanism could be the traction exerted on the photoreceptors by the contracting fibrin meshwork, which is formed within the clot. In addition, iron derived from the blood could induce direct toxicity, while the hemorrhage can also act as a barrier to nutrients and waste products, which otherwise pass between the retina and the RPE. ${ }^{2}$

Various treatment modalities have been used for SMH due to AMD, including intravitreal gas, vitrectomy, macular translocation, RPE patch grafting, submacular clot evacuation, photodynamic therapy, pneumatic displacement, and tissue plasminogen
Correspondence: Dimitrios Karagiannis Second Department of Ophthalmology, Ophthalmiatrion Athinon, 4 Sina Street, Athens 10678, Greece

Tel +30 2l 32052800

Email dimitrioskaragiannis@doctors. org.uk 
activator (tPA). ${ }^{2,4-7}$ However, all these approaches have serious complications and therefore have been limited. ${ }^{2}$ Intravitreal anti-vascular endothelial growth factor (antiVEGF) agents are the gold standard for treatment of wet AMD. Large clinical trials have shown the efficacy and safety of intravitreal ranibizumab (Lucentis; Novartis International AG, Basel, Switzerland) in patients with neovascular AMD. ${ }^{8}$ Nevertheless, it should be mentioned that patients with hemorrhage $>50 \%$ of choroidal neovascularization were excluded in the aforementioned trials. In addition, the location of the SMH has not been previously examined with respect to the anatomical and functional outcomes after treatment in patients with wet AMD. In light of this, the purpose of this study was to evaluate the efficacy and safety of intravitreal ranibizumab for the treatment of SMH due to AMD in a long-term follow-up of 12 months, evaluating the potential role of SMH location in the final outcome after treatment.

\section{Subjects and methods}

This retrospective, observational study comprised 12 patients with SMH secondary to neovascular AMD who were treated with intravitreal ranibizumab at Ophthalmiatrion Athinon. The study was in accordance with the tenets of the Helsinki Declaration and was approved by the institutional review board of Ophthalmiatrion Athinon. Written informed consent was obtained by all participants before treatment.

Inclusion criteria were age $>50$ years, diagnosis of treatment naïve neovascular AMD with SMH comprising greater than $50 \%$ of the lesion, and at least 12-month follow-up and treatment with intravitreal ranibizumab. Diagnosis of choroidal neovascularization was confirmed by fluorescein angiography (FA). Patients who had previously received treatment or had evidence of end-stage AMD were excluded from the study. Furthermore, patients with ocular diseases, such as glaucoma, diabetic retinopathy, retinal vascular occlusion, retinal detachment, vitreoretinal interface diseases, or inflammatory disorders were excluded.

All participants had undergone thorough ophthalmologic examination at baseline, including best-corrected VA (BCVA) measurement by means of Snellen charts (described in decimal scale), slit-lamp biomicroscopy, optical coherence tomography (OCT) and FA using Spectralis (Heidelberg Engineering, Heidelberg, Germany). All patients received three consecutive monthly intravitreal injections of $0.5 \mathrm{mg} / 0.05 \mathrm{~mL}$ ranibizumab and as needed thereafter if visual deterioration more than one Snellen line or evidence of persistent/recurrent fluid/hemorrhage on OCT were observed.
All injections were performed under standard sterile conditions. Topical antibiotics were administered to all patients four times a day for 1 day before and for 5 days after the injection. The minimum interval between two intravitreal injections was 4 weeks.

Patients were examined 1 month after injection and monthly thereafter. At each follow-up visit, BCVA measurement and OCT were performed, while FA was done only at the examiner's discretion and not at every postinjection evaluation. All participants had at least 12 months' follow-up. Central foveal thickness was not included in our analysis, since its measurement is not accurate in cases of SMH. The number of injections was also recorded. Safety was assessed by ophthalmic examination and report of systemic adverse effects. Data were analyzed using paired Student's $t$-test for comparisons of BCVA pre- and posttreatment. $P<0.05$ was considered significant. Statistical analysis was performed using SPSS 22.0 (IBM, Armonk, NY, USA).

\section{Results}

Table 1 shows the demographic and clinical characteristics of the study sample. The mean age of patients was $80.3 \pm 3.6$ years. Five patients $(41.7 \%)$ were males, and seven $(58.3 \%)$ females. BCVA at baseline was 0.28 \pm 0.24 (decimal scale), and differed significantly compared to month $12(0.38 \pm 0.23$, $P=0.006) ; 41.7 \%$ of patients showed improvement in BCVA of two or more Snellen lines, and $41.7 \%$ presented stabilization. Three patients presented recurrence in $\mathrm{SMH}$ despite treatment.

Five of 12 patients $(41.7 \%)$ presented SMH surrounding the foveal area in $360^{\circ}$ (group I), while seven patients $(58.3 \%$ ) had SMH which was adjacent to the fovea but did not encircle the fovea (group II). In group II, patients presented better anatomical and visual outcomes after treatment, as shown in Figures 1 and 2 and Table 1. The mean number of injections was $7.3 \pm 2.9$ for the 1 -year follow-up. No significant systemic or ophthalmic adverse events were registered during the 12-month follow-up.

\section{Discussion}

The principal message of this study is that patients with SMH due to AMD presented VA improvement or stabilization after intravitreal ranibizumab. Specifically, $41.7 \%$ of patients in our study showed significant improvement in VA and $41.7 \%$ stabilization, while mean BCVA was improved from 0.28 to 0.38 at the 12 -month follow-up. It is also worthy to note that the location of the SMH with respect to the fovea is a significant factor to predict final outcome, 
Table I Demographic and clinical characteristics of our study sample

\begin{tabular}{|c|c|c|c|c|c|c|c|c|c|c|c|}
\hline Case & Age, y & Gender & $\begin{array}{l}\text { SMH } \\
\text { location }\end{array}$ & $\begin{array}{l}\text { VA } \\
\text { baseline }\end{array}$ & $\begin{array}{l}\text { VA } \\
\text { month I }\end{array}$ & $\begin{array}{l}\text { VA } \\
\text { month } 2\end{array}$ & $\begin{array}{l}\text { VA } \\
\text { month } 3\end{array}$ & $\begin{array}{l}\text { VA } \\
\text { month } 6\end{array}$ & $\begin{array}{l}\text { VA } \\
\text { month I2 }\end{array}$ & Injections & $\begin{array}{l}\text { SMH } \\
\text { recurrence }\end{array}$ \\
\hline 1 & 81 & $\mathrm{~F}$ & Group II & 0.90 & 0.80 & 0.90 & 0.80 & 1.00 & 0.90 & 12 & 0 \\
\hline 2 & 81 & $M$ & Group II & 0.20 & 0.20 & 0.20 & 0.20 & 0.40 & 0.40 & 6 & 0 \\
\hline 3 & 88 & $M$ & Group I & 0.40 & 0.40 & 0.50 & 0.50 & 0.50 & 0.20 & 12 & I \\
\hline 4 & 82 & $\mathrm{~F}$ & Group II & 0.05 & 0.30 & 0.30 & 0.30 & 0.50 & 0.50 & 5 & 0 \\
\hline 5 & 80 & $\mathrm{~F}$ & Group I & 0.40 & 0.40 & 0.60 & 0.30 & 0.30 & 0.40 & 7 & 0 \\
\hline 6 & 76 & $\mathrm{~F}$ & Group II & 0.50 & 0.50 & 0.50 & 0.50 & 0.50 & 0.50 & 4 & 0 \\
\hline 7 & 79 & $\mathrm{~F}$ & Group II & 0.30 & 0.40 & 0.40 & 0.50 & 0.50 & 0.50 & 6 & 0 \\
\hline 8 & 82 & $M$ & Group II & 0.20 & 0.20 & 0.30 & 0.40 & 0.40 & 0.40 & 5 & 0 \\
\hline 9 & 78 & $\mathrm{~F}$ & Group I & 0.20 & 0.05 & 0.10 & 0.05 & 0.05 & 0.10 & 10 & 2 \\
\hline 10 & 83 & $M$ & Group I & 0.10 & 0.10 & 0.05 & 0.10 & 0.10 & 0.10 & 8 & I \\
\hline II & 74 & $M$ & Group I & 0.05 & 0.05 & 0.10 & 0.10 & 0.10 & 0.10 & 9 & 0 \\
\hline 12 & 80 & $\mathrm{~F}$ & Group II & 0.10 & 0.10 & 0.20 & 0.40 & 0.40 & 0.40 & 4 & 0 \\
\hline
\end{tabular}

Notes: Group I, SMH surrounding $360^{\circ}$ of the fovea; group II, SMH adjacent to the fovea but not encircling it.

Abbreviations: F, female; M, male; VA, visual acuity; SMH, submacular hemorrhage; $y$, years.

with patients having $\mathrm{SMH} 360^{\circ}$ around the fovea presenting worse results.

Before the widespread introduction of anti-VEGF treatments, verteporfin photodynamic therapy was considered the treatment for SMH due to AMD, providing acceleration of SMH hemorrhage resolution and minimizing visual loss compared to the natural history of the disease. ${ }^{5}$ Later intravitreal injection of tPA and gas was a reasonable treatment option, as it was based on a double mechanism: enzyme-induced lysis of the clot by the tPA, and subsequent mechanical displacement
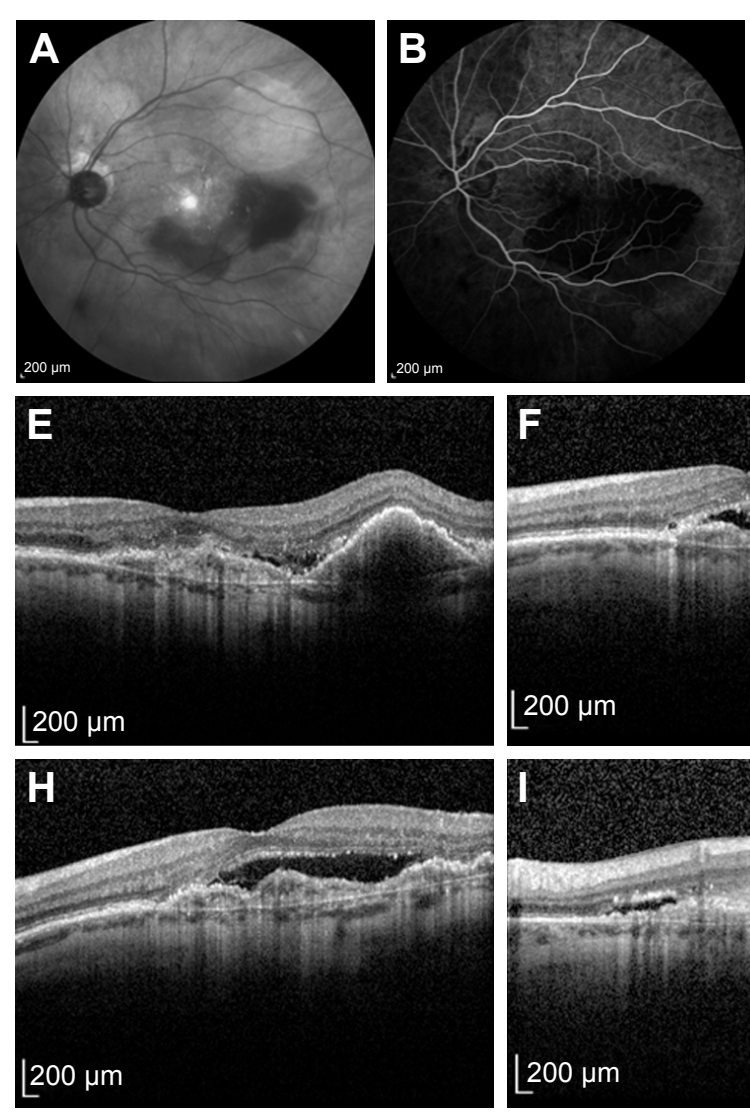
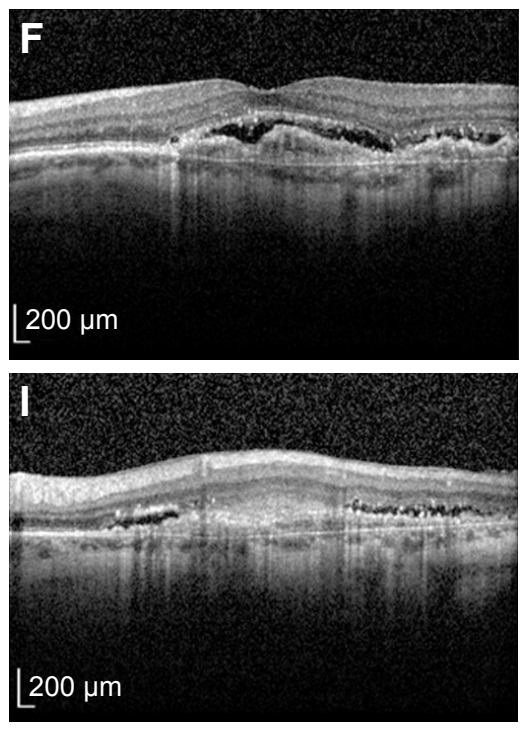
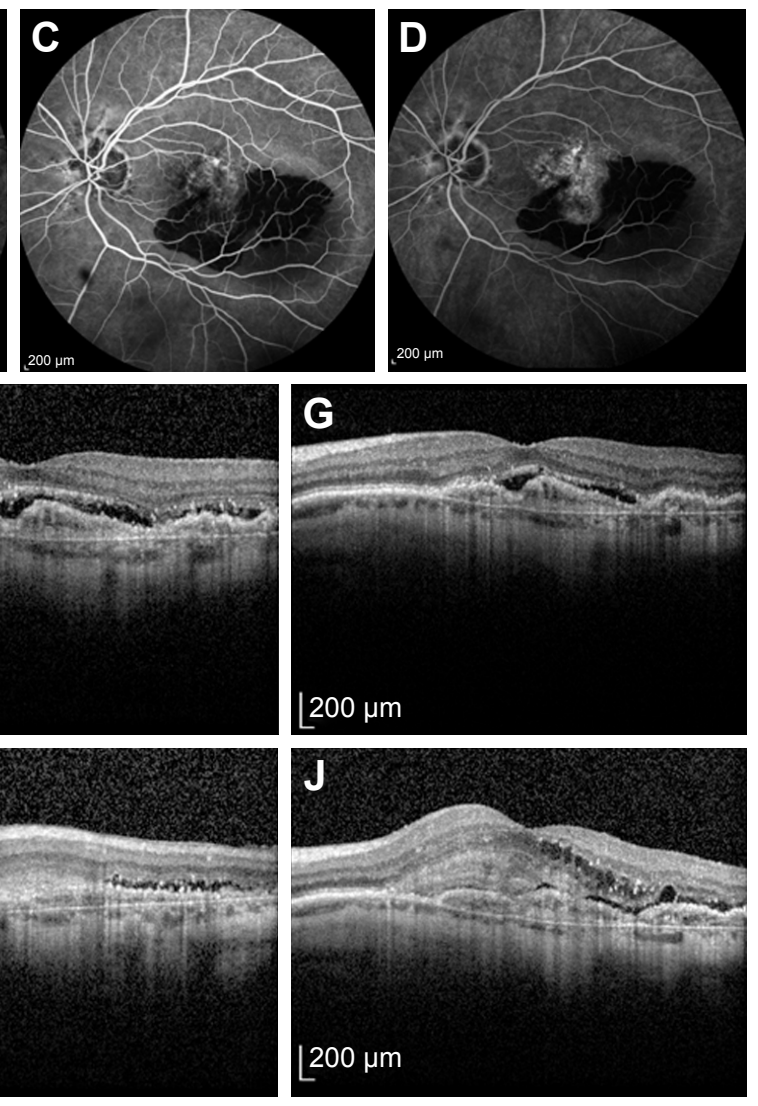

Figure I Submacular hemorrhage due to age-related macular degeneration, encircling the fovea $360^{\circ}$ at baseline.

Notes: Infrared fundus photography (A), fluorescein angiography (B-D), and B-scan optical coherence tomography (E). Visual acuity was 6/I20. B-scan optical coherence tomography at I month (F), 3 months $(\mathbf{G}), 6$ months $(\mathbf{H}), 9$ months $(\mathbf{I})$, and I year $(\mathbf{J})$ after initiation of intravitreal ranibizumab treatment, showing fibrotic tissue and poor visual acuity of $6 / 60$. 

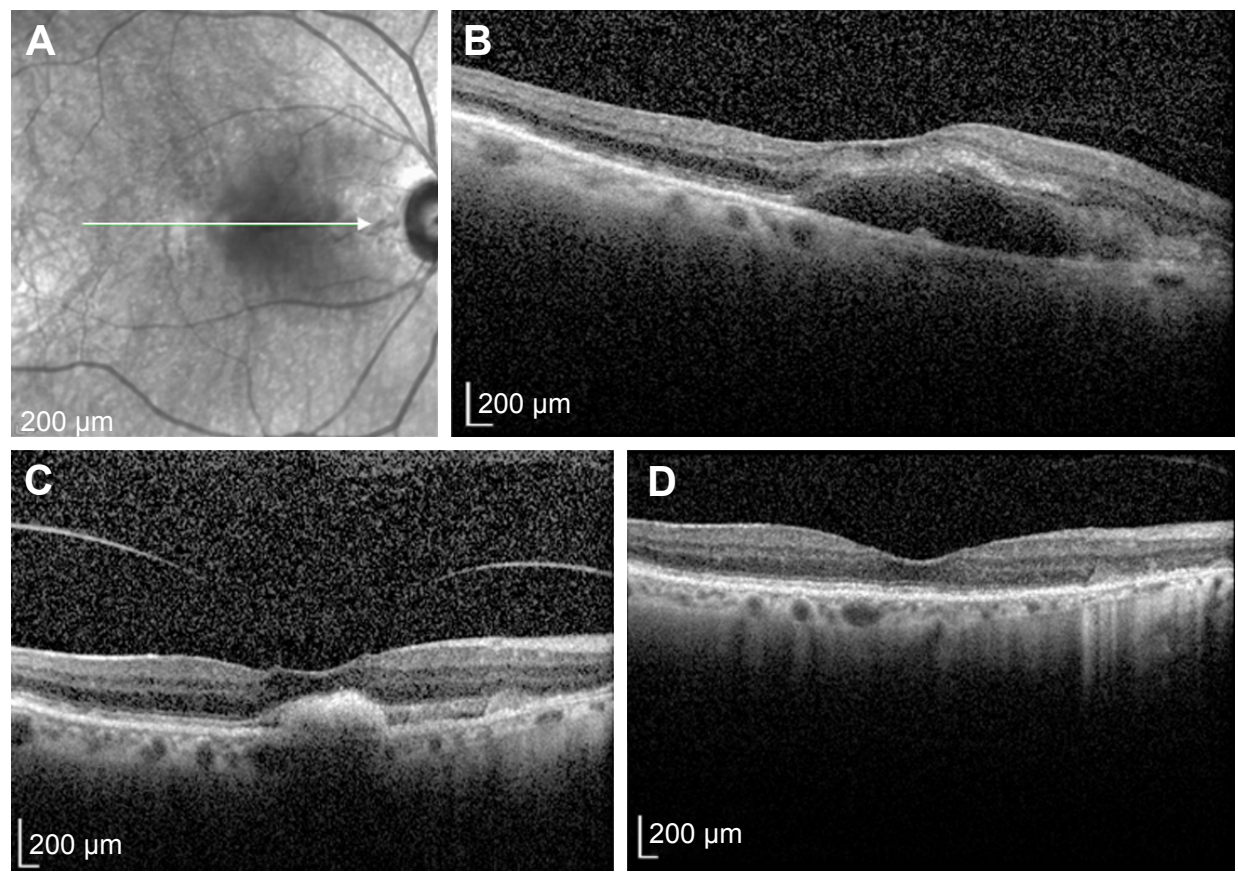

Figure 2 Submacular hemorrhage adjacent to the fovea, but not encircling the fovea at baseline.

Notes: Infrared fundus photography (A) and optical coherence tomography (B). The arrow in $\mathbf{A}$ indicates the section of optical coherence tomography that was performed. Visual acuity was 6/60. Optical coherence tomography at month 6 (C) and month 12 (D) after initiation of intravitreal ranibizumab, showing great improvement with absorption of the hemorrhage. Visual acuity was $6 / 24$.

of the liquefied blood by the gas bubble. However, this treatment option fails to treat the underlying cause, ie, the neovascular AMD. ${ }^{4}$ Accordingly, vitrectomy with tPA and with or without gas has been used for SMH due to AMD with favorable results, although the potential complications of vitrectomy remain a matter of controversy. ${ }^{2}$

Nowadays, the gold standard in the treatment of neovascular AMD is anti-VEGF agents. Large randomized controlled trials have shown the efficacy and safety of antiVEGF in wet AMD, although patients with SMH involving more than $50 \%$ of the lesion were excluded. ${ }^{8}$ Several studies have suggested that bevacizumab, ranibizumab, or aflibercept provide encouraging results with moderate visual gains or stabilization in patients with SMH due to AMD. ${ }^{9-13}$ Additionally, anti-VEGF agents have been combined with other treatment options, such as gas, tPA, or vitrectomy, offering variable results. ${ }^{14-16}$ Specifically, Altaweel et al reported an improvement in a prospective study of more than three lines (15 or more letters) in $32.1 \%$ of 78 eyes with SMH due to AMD receiving intravitreal bevacizumab or ranibizumab, while all patients presented either stabilization or improvement of VA. ${ }^{10}$ This observation was in line with Shienbaum et al and Kim et al, who also found improvement in VA of more than three lines in $60 \%$ of patients and fewer than three lines in $30 \%-40 \%$ of patients with SMH treated with bevacizumab or ranibizumab in their retrospective studies.., 11
Accordingly, Shin et al used intravitreal aflibercept for the treatment of 25 eyes with SMH due to AMD and found that aflibercept was an effective treatment option, showing improvement in BCVA from 0.79 to $0.54 \log$ MAR and significant decrease in SMH area at the 6-month follow-up. ${ }^{13}$

This study also demonstrated improvement or stabilization of VA in patients with SMH due to AMD at the 1-year follow-up. Regression of SMH was observed in all patients after treatment, while recurrence occurred in three of 12 patients (25\%) at the 12-month follow-up. Scupola et al reported bleeding recurrence in $4 \%$ of patients and vitreous hemorrhage in $6.6 \%$ of patients over a natural course of wet AMD. ${ }^{3}$ Kim et al reported vitreous hemorrhage in $12 \%$ of cases after bevacizumab or ranibizumab treatment, ${ }^{11}$ while Shin et al demonstrated recurrence of bleeding in $7 \%$ of cases after aflibercept use. ${ }^{13}$ An interesting finding of this study was that the location of SMH could be a predictor of final outcome, since patients with SMH surrounding the fovea $360^{\circ}$ presented persistent/recurrent fluid in OCT (Figure 1) and had lower VA than patients with SMH adjacent to the fovea (Figure 2).

Potential limitations of this study pertain to its retrospective nature and small sample size. In addition, there was a lack of control group without use of intravitreal ranibizumab. However, we had a relatively long follow-up period of 12 months and pointed to the location of SMH, which has 
not been previously described. Further randomized studies with large samples comparing the three anti-VEGF agents, ie, bevacizumab, ranibizumab, and aflibercept, or other treatment modalities are needed to evaluate the optimal treatment for SMH due to wet AMD. In conclusion, intravitreal ranibizumab seems to be safe and effective, either improving or stabilizing VA in patients with SMH due to wet AMD. The location of the SMH may predict the final outcome after treatment. Further prospective studies are warranted to validate our results.

\section{Disclosure}

The authors report no conflicts of interest in this work.

\section{References}

1. Hong T, Mitchell P, Rochtchina E, Fong CS, Chia EM, Wang JJ. Longterm changes in visual acuity in an older population over a 15 -year period: the Blue Mountains Eye Study. Ophthalmology. 2013;120(10): 2091-2099.

2. Stanescu-Segall D, Balta F, Jackson TL. Submacular hemorrhage in neovascular age-related macular degeneration: a synthesis of the literature. Surv Ophthalmol. 2016;61(1):18-32.

3. Scupola A, Coscas G, Soubrane G, Balestrazzi E. Natural history of macular subretinal hemorrhage in age-related macular degeneration. Ophthalmologica. 1999;213(2):97-102.

4. Sobolewska B, Utebey E, Bartz-Schmidt KU, Tatar O. Long-term visual outcome and its predictive factors following treatment of acute submacular hemorrhage with intravitreous injection of tissue plasminogen factor and gas. J Ocul Pharmacol Ther. 2014;30(7):567-572.

5. Bakri SJ, Nickel J, Yoganathan P, Beer PM. Photodynamic therapy for choroidal neovascularization associated with submacular hemorrhage in age-related macular degeneration. Ophthalmic Surg Lasers Imaging. 2006;37(4):278-283.

6. Hassan AS, Johnson MW, Schneiderman TE, et al. Management of submacular hemorrhage with intravitreous tissue plasminogen activator injection and pneumatic displacement. Ophthalmology. 1999;106(10): 1900-1906.
7. Shin JY, Lee JM, Byeon SH. Anti-vascular endothelial growth factor with or without pneumatic displacement for submacular hemorrhage. Am J Ophthalmol. 2015;159(5):904-914.

8. Rosenfeld PJ, Brown DM, Heier JS, et al. Ranibizumab for neovascular age-related macular degeneration. $N$ Engl J Med. 2006;355(14): $1419-1431$.

9. Shienbaum G, Filho CA, Flynn HW Jr, Nunes RP, Smiddy WE, Rosenfeld PJ. Management of submacular hemorrhage secondary to neovascular age-related macular degeneration with anti-vascular endothelial growth factor monotherapy. Am J Ophthalmol. 2013;155(6): 1009-1013.

10. Altaweel MM, Daniel E, Martin DF, et al. Outcomes of eyes with lesions composed of $>50 \%$ blood in the Comparison of Age-Related Macular Degeneration Treatments trials (CATT). Ophthalmology. 2015; 122(2):391-398.

11. Kim HS, Cho HJ, Yoo SG, et al. Intravitreal anti-vascular endothelial growth factor monotherapy for large submacular hemorrhage secondary to neovascular age-related macular degeneration. Eye (Lond). 2015; 29(9):1141-1151.

12. Iacono P, Parodi MB, Introini U, La Spina C, Varano M, Bandello F. Intravitreal ranibizumab for choroidal neovascularization with large submacular hemorrhage in age-related macular degeneration. Retina. 2014:34(2):281-287.

13. Shin KH, Lee TG, Kim JH, et al. The efficacy of intravitreal aflibercept in submacular hemorrhage secondary to wet age-related macular degeneration. Korean J Ophthalmol. 2016;30(5):369-376.

14. Shin JY, Choi HJ, Chung B, Choi M, Lee J, Byeon SH. Anti-vascular endothelial growth factor with gas for submacular hemorrhage. Optom Vis Sci. 2016;93(2):173-180.

15. González-López JJ, McGowan G, Chapman E, Yorston D. Vitrectomy with subretinal tissue plasminogen activator and ranibizumab for submacular haemorrhages secondary to age-related macular degeneration: retrospective case series of 45 consecutive cases. Eye (Lond). 2016;30(7): 929-935.

16. Kitagawa Y, Shimada H, Mori R, Tanaka K, Yuzawa M. Intravitreal tissue plasminogen activator, ranibizumab, and gas injection for submacular hemorrhage in polypoidal choroidal vasculopathy. Ophthalmology. 2016;123(6):1278-1286.
Clinical Interventions in Aging

\section{Publish your work in this journal}

Clinical Interventions in Aging is an international, peer-reviewed journal focusing on evidence-based reports on the value or lack thereof of treatments intended to prevent or delay the onset of maladaptive correlates of aging in human beings. This journal is indexed on PubMed Central, MedLine,

\section{Dovepress}

CAS, Scopus and the Elsevier Bibliographic databases. The manuscript management system is completely online and includes a very quick and fair peer-review system, which is all easy to use. Visit http://www.dovepress. com/testimonials.php to read real quotes from published authors. 